\title{
Alpha-methylacyl-CoA racemase as a marker in the differential diagnosis of metanephric adenoma
}

\author{
Semra Olgac, Brian Hutchinson, Satish K Tickoo and Victor E Reuter \\ Department of Pathology, Memorial Sloan-Kettering Cancer Center, New York, NY, USA
}

\begin{abstract}
Metanephric adenoma (MA), a well-described renal neoplasm, usually behaves in a benign fashion. It may have areas that are morphologically similar to papillary renal cell carcinoma (RCC) type, or epithelial (tubular predominant) type Wilms' tumor. Prior immunohistochemical studies of MA have reported variable staining patterns. Alpha-methylacyl-CoA racemase (AMACR), a molecular marker for prostate carcinoma, has subsequently been found to be overexpressed in breast, colorectal and ovarian cancers, among others. Recent microarray analysis of renal tumors has shown an increase of AMACR mRNA levels in papillary RCC but not in other subtypes. We investigated the utility of immunohistochemical staining for AMACR, cytokeratin 7(CK7), CD57 and WT1 to differentiate between the above-mentioned three neoplasms. Immunohistochemical stains were performed on paraffin-embedded tissue sections from 25 papillary RCC, 10 MAs and eight Wilms' tumors. AMACR was positive in one (10\%) of 10 MAs and $24(96 \%)$ of 25 papillary RCC, while it was negative in all Wilms' tumors. CK7 was positive in 20 of 25 papillary RCCs, focally positive in one Wilms' tumor and was negative in all MAs. CD57 was positive in all six MAs that were stained, focally positive in one of 25 papillary RCC and one of eight Wilms' tumors. WT1 was positive in seven of 10 MAs, three of 25 papillary RCCs and all eight Wilms' tumors. In conclusion, diffuse and strong immunoreactivity for AMACR may be useful in differentiating papillary RCC from MA but a panel which includes AMACR, CK7 and CD57 is better in this differential diagnosis. AMACR is not helpful in differentiating MA from Wilms' tumor, but CD57 is helpful in this differential diagnosis. WT1 may be useful in separating Wilms' tumor from MA and papillary RCC but is not helpful in differentiating MA from papillary RCC.
\end{abstract}

Modern Pathology (2006) 19, 218-224. doi:10.1038/modpathol.3800520

Keywords: metanephric adenoma; papillary renal cell carcinoma; Wilms' tumor; racemase

Metanephric adenoma (MA) is a relatively rare though well-described benign neoplasm of the kidney. ${ }^{1-7}$ The previously published series suggest that MAs are related to the proximal tubule of the fetal kidney or nephrogenic rests, and both the histologic and ultrastructural features of this tumor suggest similarities to metanephric tubular epithelium. ${ }^{1,8,9}$ Morphologically, MA shares features with papillary renal cell carcinoma (PRCC) type I, particularly the solid variant ${ }^{10}$ and the epithelial component of the epithelial (tubular predominant) type Wilms' tumor without anaplasia (WT). ${ }^{11}$ Some genetic studies have suggested a close relationship

Correspondence: Dr VE Reuter, MD, Department of Pathology, Memorial Sloan-Kettering Cancer Center, New York, NY 10021, USA.

E-mail: reuterv@mskcc.org

Presented in part at the 93rd Annual Meeting of USCAP, March 2004, Vancouver, Canada.

Received 24 June 2005; revised and accepted 18 October 2005 between MA and PRCC by showing trisomies of chromosomes 7 and 17, and loss of sex chromosomes by classic cytogenetics ${ }^{12}$ or FISH $^{13}$ in both, but others disagree, having found normal or variants of normal karyotypes in MA. ${ }^{1,2,14}$ Most investigators now feel that these tumors are not genetically related. ${ }^{15,16}$ None of the studies have shown abnormalities of $11 \mathrm{p}$ in MA, as are seen in most syndromic and up to $15 \%$ of sporadic WT, arguing against a relationship with WT. ${ }^{17}$ Tamas et al delineated a tumor suppressor gene on chromosome 2 in MA by microsatellite allelotyping, suggesting that MA is a genetic entity and is different from both WT and PRCC. ${ }^{16}$

Prior immunohistochemical studies of MA have shown no consistent staining patterns. ${ }^{1-3}$ Most tumors are reported to be negative for EMA with variable staining for cytokeratins. Positivity for CD57 (usually diffuse) ${ }^{2,18}$ and focal positivity for CK7 is often present. ${ }^{1-3,18}$ WT1 has also been reported to be positive. ${ }^{2,18}$ 
The WT gene WT1 encodes a protein that acts as a transcription activator and tumor suppressor and is thought to be essential in the development of embryonic kidney, ovaries and testes. ${ }^{19}$ In renal tumors, WT1 expression is seen in Wilms' tumor, cystic partially differentiated nephroblastoma, rhabdoid tumor ${ }^{20,21}$ and MAs. ${ }^{1,18}$ CK7 is a type II (basic) keratin with a molecular weight of $54 \mathrm{kD} .^{22}$ It is known to be positive in tumors from various sites including most cases of PRCC. CD57 is a glycoprotein that is expressed on a wide variety of normal and neoplastic tissues; however, its function and biochemical activity are not known. ${ }^{23}$ CD57 is expressed in the proximal tubules in the adult kidney. ${ }^{21}$

Alpha-methylacyl-CoA racemase (AMACR) is a mitochondrial and peroxisomal enzyme ${ }^{24,25}$ that catalyzes the racemization of alpha-methyl, branched carboxylic coenzyme A thioesters. ${ }^{26}$ Recently, several groups have shown that AMACR is potentially an important biomarker for prostate cancer. ${ }^{27-29}$ It is overexpressed in tumors arising in other organ systems as well. ${ }^{30}$ Recent DNA microarray studies found expression of high levels of AMACR in PRCC, but not in the other subtypes of RCC. ${ }^{31-34}$

The purpose of this study was to compare the immunophenotypic features of MA, WT and PRCC, and to evaluate an antibody panel that includes AMACR to aid in distinguishing them.

\section{Materials and methods}

In all, 10 MAs and eight nephroblastomas, epithelial (tubular predominant) type without anaplasia (WT) were identified from the files of Department of Pathology at the Memorial Sloan Kettering Cancer Center and from the consultation files of one of the authors (VER). A total of 25 low-grade (type I) PRCCs were retrieved from the department files of Memorial Sloan Kettering Cancer Center.

All original slides from each case were reviewed. Paraffin blocks or unstained slides (from the consultation cases) were available for all cases. Unstained $4 \mu \mathrm{m}$ sections were cut from the paraffin block selected for each case and deparaffinized by routine techniques. Immunohistochemical stains were performed using the streptavidin-biotin peroxidase technique. Appropriate positive and negative control slides were stained in parallel.
Antibodies, their sources, their dilutions and pretreatments are listed in Table 1.

The extent of immunolabeling was categorized into diffuse (staining in $50-100 \%$ of cells) or focal (staining in $5-50 \%$ of cells). The staining intensity of each case was scored as positive, weakly positive or negative. Thus, neoplasms scored as positive showed either diffuse or focal, strong nuclear staining for WT1 and/or strong cytoplasmic staining for AMACR, CD57 and CK7, while the tumors scored as weakly positive showed only faint cytoplasmic or nuclear labeling. Neoplasms scored as negative showed less than $5 \%$ of cells with cytoplasmic or nuclear staining for the abovementioned reagents.

\section{Results}

Microscopically MAs were usually unencapsulated but were sharply demarcated from the adjacent kidney parenchyma. The tumors were cellular with tightly packed acini, occasional tubules and solid areas (Figure 1a). 'Glomeruloid bodies' that are formed by the invagination of tumor cells into tubular lumina were observed in six cases. These structures frequently were associated with psammoma bodies. The cells had scant cytoplasm with round to oval uniform nuclei with delicate chromatin and inconspicuous nucleoli. No mitotic figures were present.

The papillary RCCs that were selected for this study were low-grade 'type I' tumors. A total of 10 cases were solid (glomeruloid) variants of PRCC and did not show true papillae but were composed of solid sheets of cells containing distinct micronodules that resembled abortive papillae. They had the appearance of the 'glomeruloid bodies' seen in MA, while other areas showed a tubular pattern. The remaining tumors predominantly showed a papillary growth pattern (Figure 1b) with occasional aggregates of macrophages distending the fibrovascular cores. The cells lining the papilla and tubules as well as those forming the micronodules were similar, with scant to ample amphophilic to basophilic cytoplasm, vesicular nuclei, open chromatin and conspicuous to occasional prominent nucleoli.

All Wilms' tumors that were included in this study showed favorable histology with a triphasic pattern and a predominance of an epithelial component (Figure 1c). The epithelial areas were com-

Table 1 Immunoreagents used in the differential diagnosis of metanephric adenoma

\begin{tabular}{llll}
\hline Reagent & Source & Pretreatment \\
\hline AMACR & Zeta Corporation, Sierramadre, CA, USA & EDTA \\
WT1 & Santa Cruz, CA, USA & Citric acid & $1: 160$ \\
CK7 & Dako Corporation, Carpinteria, CA, USA & Protease XIV & $1: 4000$ \\
CD57 & Beckton Dickinson, San Jose, CA, USA & Protease XIV & $1: 20000$ \\
\hline
\end{tabular}



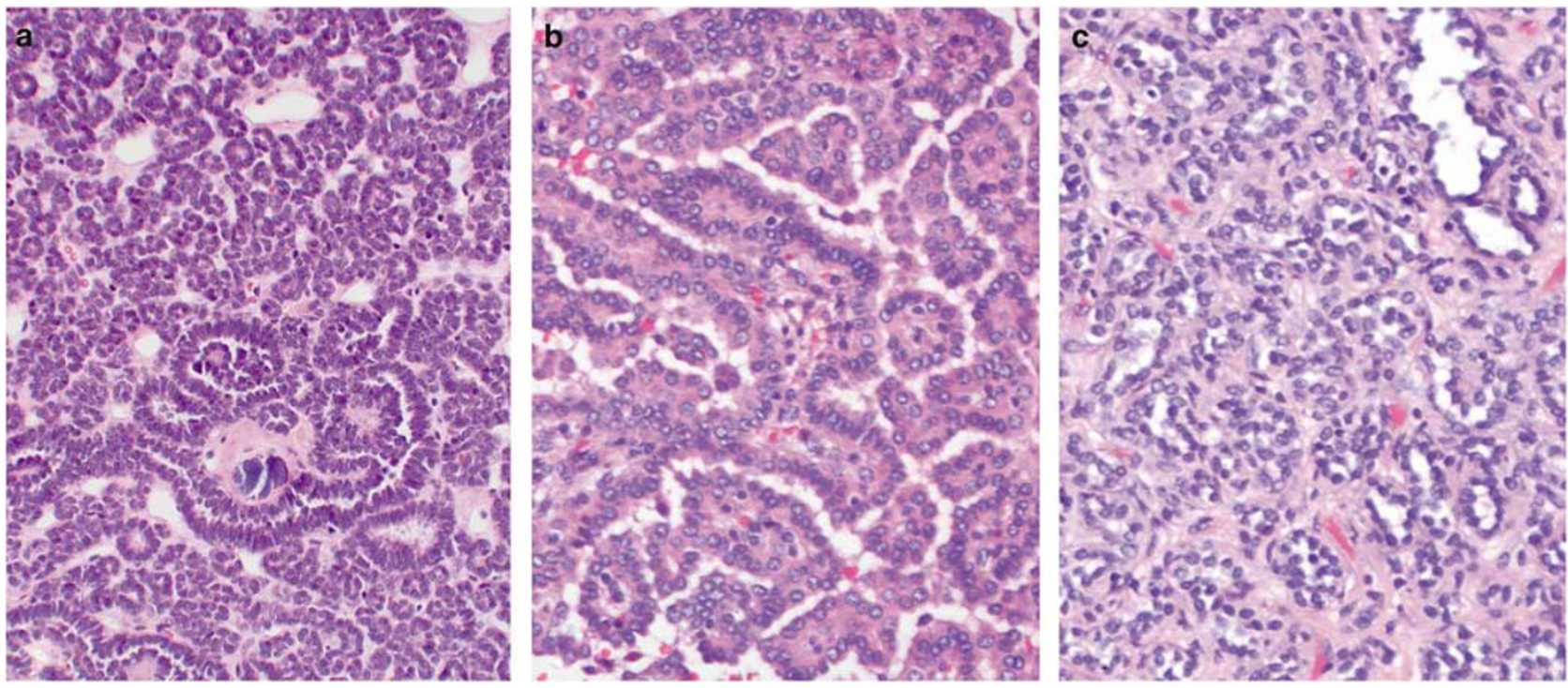

Figure 1 (a) Metanephric adenoma showing tightly packed acini and 'glomeruloid bodies'. (b) Papillary renal cell carcinoma, type I. (c) Wilms' tumor with predominant epithelial component.

Table 2 Results of staining with AMACR, CK7, WT1 and CD57 antibodies

\begin{tabular}{|c|c|c|c|c|c|c|c|c|}
\hline & \multicolumn{2}{|c|}{$A M A C R$} & \multicolumn{2}{|c|}{$C K 7$} & \multicolumn{2}{|c|}{ WT1 } & \multicolumn{2}{|c|}{ CD57 } \\
\hline & Positive & Negative & Positive & Negative & Positive & Negative & Positive & Negative \\
\hline MA & $1(\mathrm{~F}, \mathrm{~W})$ & 9 & 0 & 10 & $7(\mathrm{~F}, 4 \mathrm{~W})$ & 3 & 6 & 0 \\
\hline PRCC & $24(23 \mathrm{D}, 3 \mathrm{~W})$ & 1 & $20(11 \mathrm{D}, 5 \mathrm{~W})$ & 5 & $3(\mathrm{~F}, \mathrm{~W})$ & 22 & $1(\mathrm{~F}, \mathrm{~S})$ & 24 \\
\hline WDWT & 0 & 8 & $1(\mathrm{~F}, \mathrm{~W})$ & 7 & $8(\mathrm{D}, \mathrm{S})$ & 0 & $1(\mathrm{~F}, \mathrm{~S})$ & 7 \\
\hline
\end{tabular}

D: diffuse; F: focal; S: strong; W: weak.

posed of closely packed tubules with uniform cells exhibiting round to oval nuclei, inconspicuous nucleoli and scant cytoplasm. These areas were morphologically very similar to MA.

Results of immunohistochemical stains for AMACR, WT1, CD57 and CK7 are summarized in Table 2. Of the MAs, one of 10 was focally and weakly positive for AMACR while the remaining tumors were negative (Figure 2a). The MA with AMACR positivity had neither glomeruloid pattern nor a significant papillary growth pattern. All MAs were negative for CK7 (Figure 3a). Seven of the 10 MAs were focally positive (four cases weakly) for WT1 (Figure 4a) and the remaining three were negative. All cases stained for antibody WT1 that contained normal kidney tissue showed nuclear immunoreactivity in the podocytes. Two of the three WT1-negative MAs did not contain adjacent normal tissue, so podocyte staining could not be evaluated. CD57 was diffusely and strongly positive in all six MAs (Figure 5a) that had available material for staining. All but one PRCC were diffusely positive for AMACR (Figure 2b) with 21 showing strong staining and three cases being weakly positive. CK7 was positive in 20 of 25 PRCCs (Figure 3b). Five of these cases were weakly positive with focal positivity seen in nine cases. Only three out of 25 PRCCs were focally and weakly positive for WT1 while the other 22 cases were negative (Figure 4b). CD57 was focally but strongly positive in only one PRCC and was negative in the remaining 24 cases (Figure $5 \mathrm{~b}$ ). This tumor had a solid growth pattern and was positive for AMACR and negative for WT1. AMACR was negative in all WTs (Figure 2c). Only one of the eight WTs was focally and weakly positive for CK7 in the epithelial component while the remaining seven cases were negative (Figure 3c). WT1 was diffusely and strongly positive in all WTs (Figure 4c). CD57 was focally and strongly positive in the epithelial component of one WT (the same tumor with CK7 positivity) and was negative in the remaining seven tumors (Figure 5c).

\section{Discussion}

The majority of the renal epithelial neoplasms can be diagnosed on the basis of morphology alone. However, examples of morphologic overlap exist between selected malignant and benign entities, as 

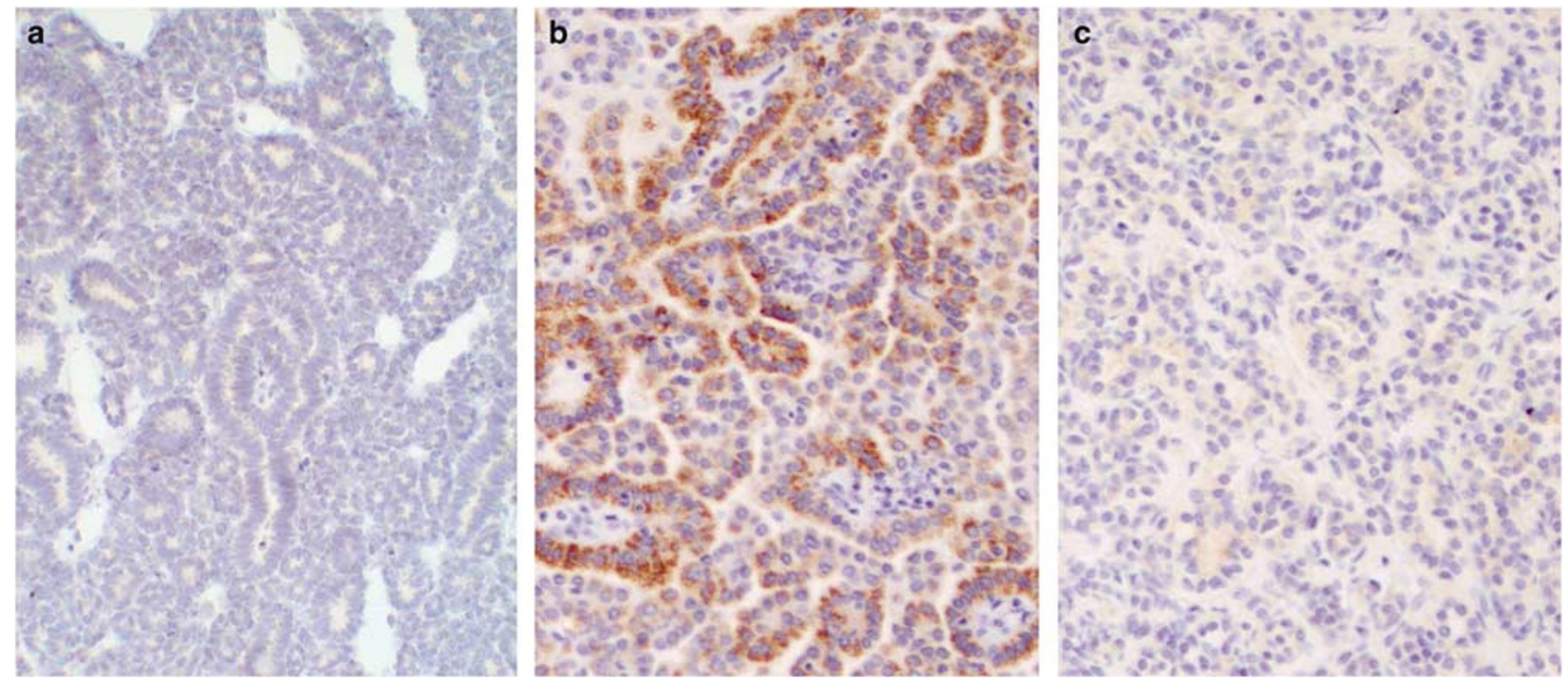

Figure 2 AMACR (a) is negative in metanephric adenoma (b) shows strong granular cytoplasmic positivity in papillary renal cell carcinoma (c) is negative in Wilms' tumor.
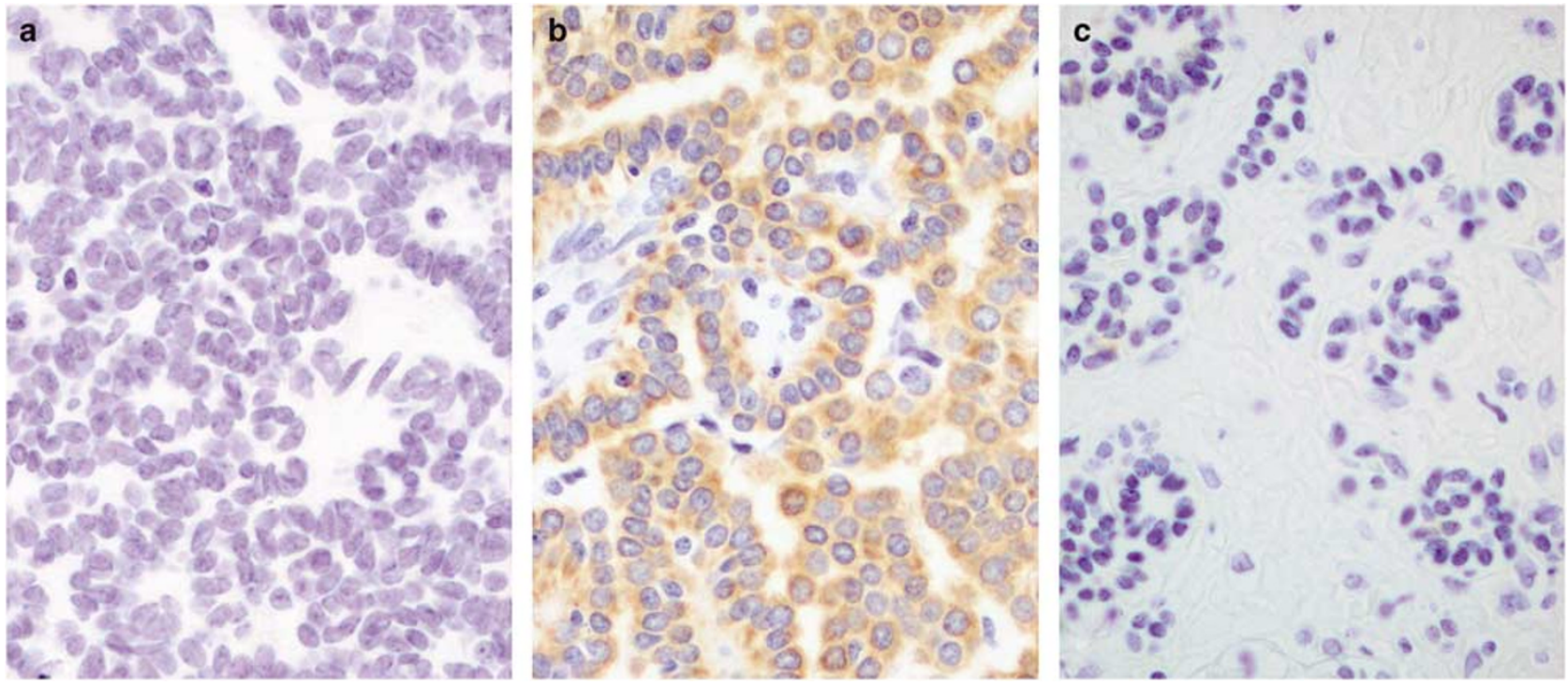

Figure 3 CK 7 is (a) negative in metanephric adenoma (b) positive in papillary renal cell carcinoma (c) negative in Wilms' tumor.

seen between MA, some cases of solid variant of papillary RCC and well-differentiated Wilms' tumor. For this reason, the use of immunohistochemical stains as a diagnostic adjunct are needed.

AMACR is an important immunohistochemical marker for the diagnosis of challenging prostate biopsies. $^{27-29}$ The expression of AMACR is not limited to the prostate since it is overexpressed in several malignant tumors of the colon, breast and ovary, among others. ${ }^{30}$ Recently, DNA microarray studies $^{31-34}$ found overexpression of AMACR in PRCC but not in other subtypes of renal tumors. AMACR has also been studied as an immunohisto- chemical marker in renal neoplasms. ${ }^{32-34}$ Takahashi et $a l^{33}$ reported strong AMACR positivity in $100 \%$ of their PRCCs and in only $10 \%$ of the conventional RCCs. All chromophobe RCCs were negative. Tretiakova et $a l^{34}$ found an average of 5.2-fold increase in AMACR mRNA levels in PRCC while immunohistochemistry demonstrated strong AMACR positivity in all of PRCC but only focal or weak reactivity in the minority of other subtypes of RCC.

MA has morphologic similarity to some lowgrade (type I) PRCC and to WT. Several studies have evaluated the immunohistochemical staining pattern of MA with variable results. ${ }^{1-3,6}$ To our 

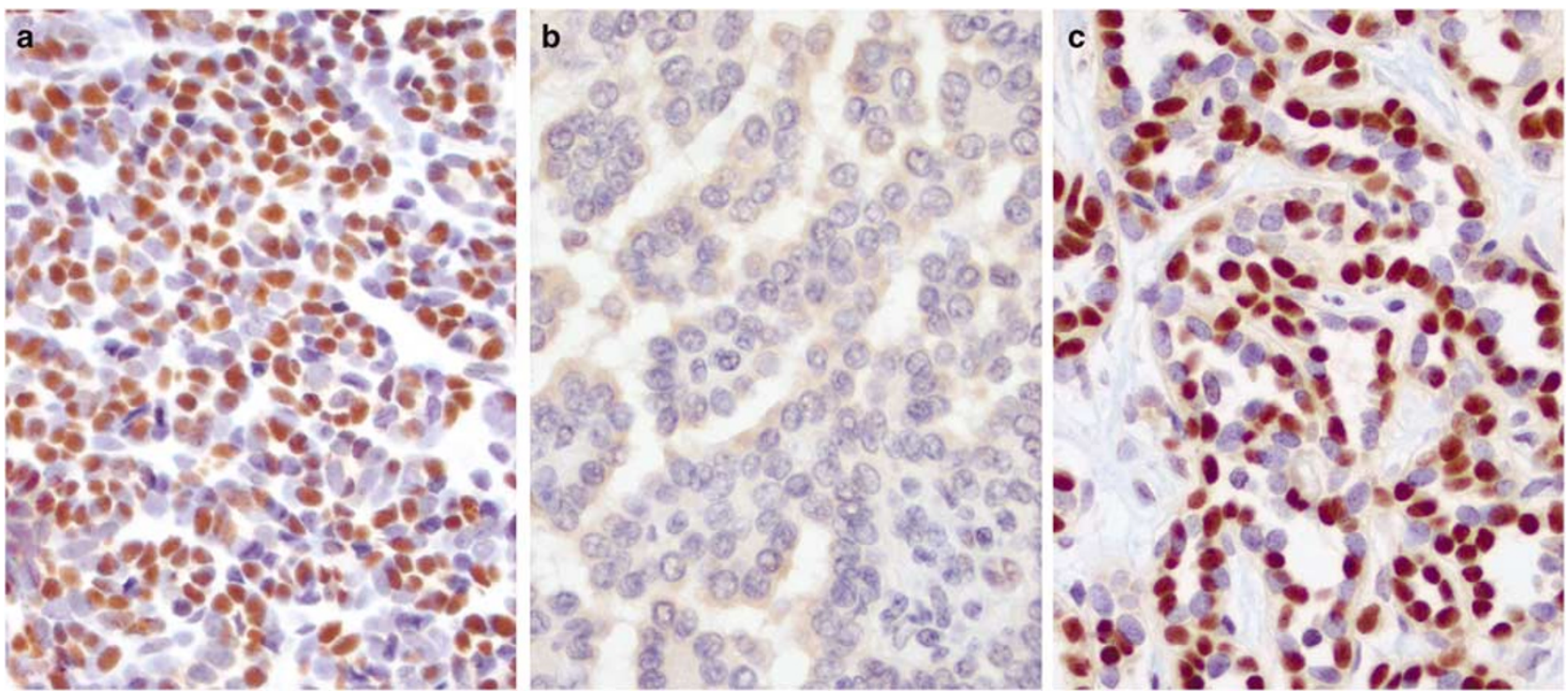

Figure 4 WT1 is (a) strongly positive in metanephric adenoma (b) negative in papillary renal cell carcinoma (c) strongly and diffusely positive in Wilms' tumor.
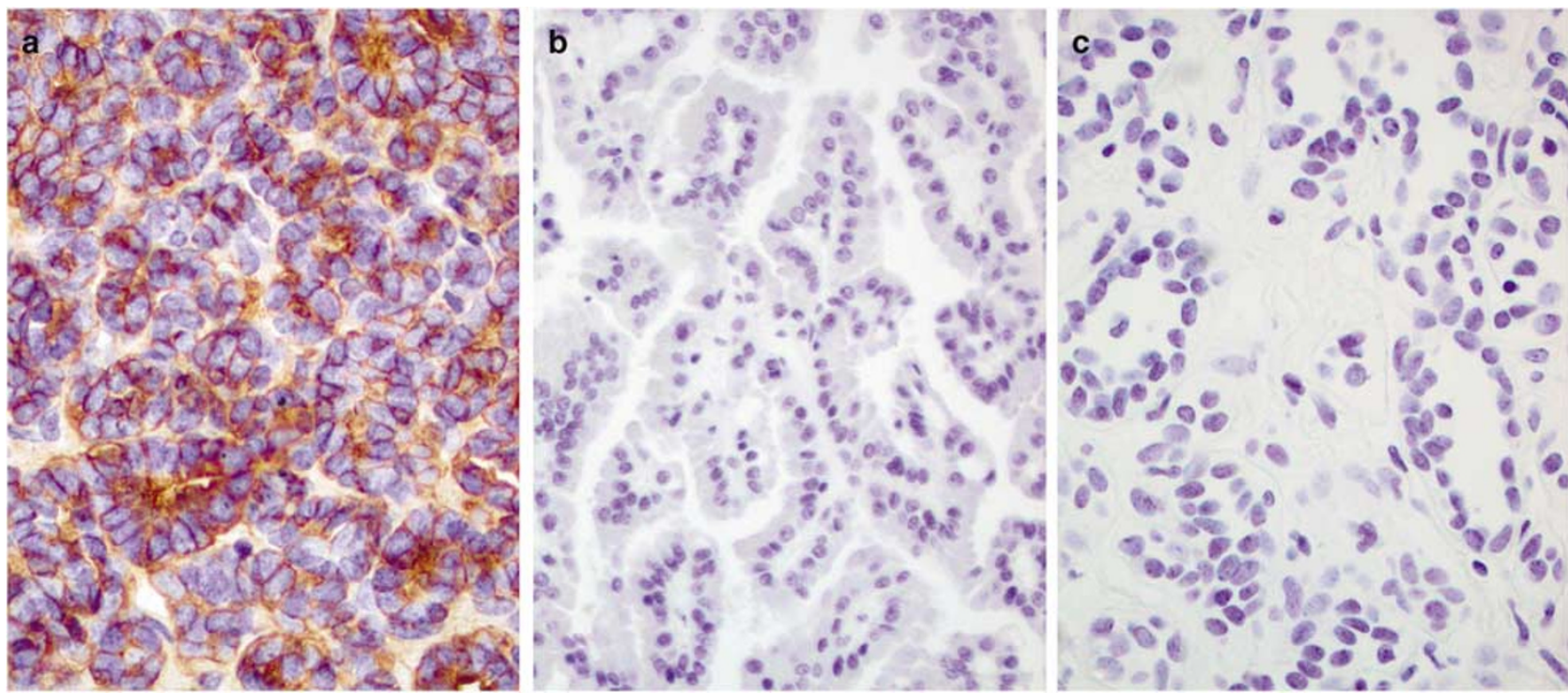

Figure 5 CD57 (a) shows strong positivity in metnephric adenoma (b) is negative in papillary renal cell carcinoma and (c) Wilms' tumor.

knowledge immunohistochemical expression of AMACR has not been studied to address this important differential diagnosis. We found AMACR to be positive in $96 \%$ of the papillary RCC, but only focally and weakly positive in $10 \%$ of the MAs, while negative in all WTs. These results suggest that it is a useful marker in the differential diagnosis of MA and PRCC. It is not helpful in differentiating MA from WT.

The majority of the reported cases of MA have been negative for EMA, variably positive or negative for cytokeratins (AE1, AE1:AE3, high molecular weight cytokeratin), and usually focally positive for CK7. ${ }^{1-3,6,18}$ However, in our study, similar to the results reported by Skinnider et al, ${ }^{35}$ CK7 was negative in all MAs. The apparent discrepant result, when compared to the other published series, is due to different scoring systems used in various studies. For example Muir et $a l^{18}$ have interpreted staining of $<5 \%$ of the tumor cells as focally positive while we accepted less than $5 \%$ staining as negative. All seven reported cases ${ }^{1,18}$ of MA were strongly positive for WT1, while in our study only $70 \%$ of the cases were positive. We assume that technical reasons, including different clones for this antibody, are responsible for this variability in results. In the study by Muir et $a l^{18}$ they have used the WT1 antibody clone $6 \mathrm{~F}-\mathrm{H} 2$ by Dako while we used clone 
C-19 12/30 by Santa Cruz. Prior studies have also reported CD57 (Leu 7) positivity in MA. ${ }^{2,18}$ Our study showed diffuse and strong positivity for CD57 in $100 \%$ of the cases stained, supporting the previously published observations.

Most type I PRCCs have been reported to be positive for CK7 and negative for WT1 and CD57. ${ }^{18}$ In the current series, CK7 was positive in only $80 \%$ of PRCC, similar to the results of Skinnider et $a l^{35}$ and Delahunt and Eble. ${ }^{36}$ WT1 was positive in $12 \%$ and CD57 was focally positive in $4 \%$ of cases.

In our study, all but one WT (focal epithelial staining) were negative for CK7 and CD57 (focal epithelial staining) supporting the previously reported results. ${ }^{18}$

In summary, even when used alone, AMACR appears to be a useful immunohistochemical marker for PRCC, and is a great adjunct in differentiating PRCC from MA. When used in combination with CK7 and CD57, AMACR will differentiate almost all MAs from PRCC. The combination of AMACR and WT1 is helpful in differentiating PRCC from WT. These immunohistochemical stains should be particularly useful in separating solid variants of PRCC from epithelial predominant WT. CD57, but not AMACR, is useful in the differential diagnosis between MA and WT.

\section{References}

1 Gatalica Z, Grujic S, Kovatich A, et al. Metanephric adenoma: histology, immunophenotype, cytogenetics, ultrastructure. Mod Pathol 1996;9:329-333.

2 Jones EC, Pins M, Dickersin GR, et al. Metanephric adenoma of the kidney. A clinicopathological, immunohistochemical, flow cytometric, cytogenetic, and electron microscopic study of seven cases. Am J Surg Pathol 1995;19:615-626.

3 Davis Jr CJ, Barton JH, Sesterhenn IA, et al. Metanephric adenoma. Clinicopathological study of fifty patients. Am J Surg Pathol 1995;19:1101-1114.

4 Brisigotti M, Cozzutto C, Fabbretti G, et al. Metanephric adenoma. Histol Histopathol 1992;7:689-692.

5 Bove KE, McAdams AJ. The nephroblastomatosis complex and its relationship to Wilms' tumor: a clinicopathologic treatise. Perspect Pediatr Pathol 1976;3:185-223.

6 Ban S, Yoshii S, Tsuruta A, et al. Metanephric adenoma of the kidney: ultrastructural, immunohistochemical and lectin histochemical studies. Pathol Int 1996;46:661-666.

7 Munichor M, Szvalb S, Cohen H. Metanephric adenoma of the kidney. Urol Int 1997;58:117-120.

8 Tannenbaum M. Ultrastructural pathology of human renal cell tumors. Pathol Annu 1971;6:249-277.

9 Katz SM, Morgan JJ. Cilia in the human kidney. Ultrastruct Pathol 1984;6:285-294.

10 Renshaw AA, Zhang $\mathrm{H}$, Corless CL, et al. Solid variants of papillary (chromophil) renal cell carcinoma: clinicopathologic and genetic features. Am J Surg Pathol 1997;21:1203-1209.

11 Argani P, Beckwith JB. Renal neoplasms of childhood. In: Carter D, Greenson J, Oberman H, Reuter VE, Stoler
MH (eds). Sternberg's Diagnostic Surgical Pathology. 4th edn. Lippincott Williams \& Wilkins: Philadelphia, 2004, pp 2001-2033.

12 Brown JA, Sebo TJ, Segura JW. Metaphase analysis of metanephric adenoma reveals chromosome Y loss with chromosome 7 and 17 gain. Urology 1996;48:473-475.

13 Brown JA, Anderl KL, Borell TJ, et al. Simultaneous chromosome 7 and 17 gain and sex chromosome loss provide evidence that renal metanephric adenoma is related to papillary renal cell carcinoma. J Urol 1997;158:370-374.

14 Granter SR, Fletcher JA, Renshaw AA. Cytologic and cytogenetic analysis of metanephric adenoma of the kidney: a report of two cases. Am J Clin Pathol 1997;108:544-549.

15 Brunelli M, Eble JN, Zhang S, et al. Metanephric adenoma lacks the gains of chromosomes 7 and 17 and loss of $\mathrm{Y}$ that are typical of papillary renal cell carcinoma and papillary adenoma. Mod Pathol 2003; 16:1060-1063.

16 Pesti T, Sukosd F, Jones EC, et al. Mapping a tumor suppressor gene to chromosome 2p13 in metanephric adenoma by microsatellite allelotyping. Hum Pathol 2001;32:101-104.

17 Lee SB, Haber DA. Wilms tumor and the WT1 gene. Exp Cell Res 2001;264:74-99.

18 Muir TE, Cheville JC, Lager DJ. Metanephric adenoma, nephrogenic rests, and Wilms' tumor: a histologic and immunophenotypic comparison. Am J Surg Pathol 2001;25:1290-1296.

19 Pritchard-Jones K, Fleming S, Davidson D, et al. The candidate Wilms' tumour gene is involved in genitourinary development. Nature 1990;346:194-197.

20 Charles AK, Mall S, Watson J, et al. Expression of the Wilms' tumour gene WT1 in the developing human and in paediatric renal tumours: an immunohistochemical study. Mol Pathol 1997;50:138-144.

21 Ramani P, Cowell JK. The expression pattern of Wilms' tumour gene (WT1) product in normal tissues and paediatric renal tumours. J Pathol 1996;179: 162-168.

22 Dabbs DJ. Carcinomatous differentiation and metastatic carcinoma of unknown primary. In: Zorab R (ed). Diagnostic Immunohistochemistry. Churchhill Livingstone: Philadelphia, PA, 2002, pp 166-167.

23 Arber DA, Weiss LM. CD57: a review. Appl Immunohistochem 1995;3:137-152.

24 Amery L, Fransen M, De Nys K, et al. Mitochondrial and peroxisomal targeting of 2-methylacyl-CoA racemase in humans. J Lipid Res 2000;41:1752-1759.

25 Ferdinandusse S, Denis S, L IJ, et al. Subcellular localization and physiological role of alpha-methylacyl-CoA racemase. J Lipid Res 2000;41:1890-1896.

26 Schmitz W, Fingerhut R, Conzelmann E. Purification and properties of an alpha-methylacyl-CoA racemase from rat liver. Eur J Biochem 1994;222:313-323.

27 Jiang Z, Woda BA, Rock KL, et al. P504S: a new molecular marker for the detection of prostate carcinoma. Am J Surg Pathol 2001;25:1397-1404.

28 Luo J, Zha S, Gage WR, et al. Alpha-methylacyl-CoA racemase: a new molecular marker for prostate cancer. Cancer Res 2002;62:2220-2226.

29 Rubin MA, Zhou M, Dhanasekaran SM, et al. alphaMethylacyl coenzyme A racemase as a tissue biomarker for prostate cancer. JAMA 2002;287:1662-1670.

30 Zhou M, Chinnaiyan AM, Kleer CG, et al. Alphamethylacyl-CoA racemase: a novel tumor marker 
over-expressed in several human cancers and their precursor lesions. Am J Surg Pathol 2002;26: 926-931.

31 Higgins JP, Shinghal R, Gill H, et al. Gene expression patterns in renal cell carcinoma assessed by complementary DNA microarray. Am J Pathol 2003;162: 925-932.

32 Jiang Z, Fanger GR, Woda BA, et al. Expression of alpha-methylacyl-CoA racemase (P504s) in various malignant neoplasms and normal tissues: astudy of 761 cases. Hum Pathol 2003;34:792-796.

33 Takahashi M, Yang XJ, Sugimura J, et al. Molecular subclassification of kidney tumors and the discovery

of new diagnostic markers. Oncogene 2003;22:68106818.

34 Tretiakova MS, Sahoo S, Takahashi M, et al. Expression of alpha-methylacyl-CoA racemase in papillary renal cell carcinoma. Am J Surg Pathol 2004;28:69-76.

35 Skinnider BF, Folpe AL, Hennigar RA, et al. Distribution of cytokeratins and vimentin in adult renal neoplasms and normal renal tissue: potential utility of a cytokeratin antibody panel in the differential diagnosis of renal tumors. Am J Surg Pathol 2005;29:747-754.

36 Delahunt B, Eble JN. Papillary renal cell carcinoma: a clinicopathologic and immunohistochemical study of 105 tumors. Mod Pathol 1997;10:537-544. 